\title{
La teología poética de Pedro Casaldáliga (I)
}

Víctor Codina

CESIP, Oruro, Bolivia.

\section{Prólogo}

\subsection{Motivación y límites}

Tal vez sea audacia, o ingenuidad, el intentar escribir sobre una persona en plena actividad apostólica y literaria como Pedro Casaldáliga. Tal vez sea ingenuidad, o audacia, presentar $a$ un autor que es, a la vez, testigo cualificado y piedra de escándalo:

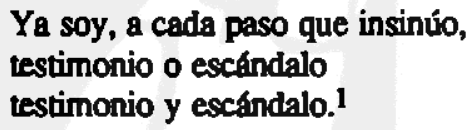

Casaldáliga es desconcertante, escribe poemas en memoria del Che y de Sandino, dedica un libro suyo de poesías a Fidel Castro y besa los féretros de los jóvenes nicas muertos por "la contra," pero al mismo tiempo advierte a la prensa:

Te engaflas, periodista,

si piensas que me pillas

disparándome fotos

mientras beso este féretro.

Yo beso a los caídos

a la luz de la Historia, bajo el sol de la Pascua 2

Y nos devela el misterio de su personalidad:

Si no sabeis quiên soy. Si os desconcierta

la amalgama de amores que cultivo:

una flor para el Che, toda la huerti

para el Dios de Jesís. Si me desvivo

por bendecir una alambrada abiert:

y el mito de una aldea redivivo.

Si tiento a Dios par Nicaragua alerta,

por este Continente ain cautivo. 


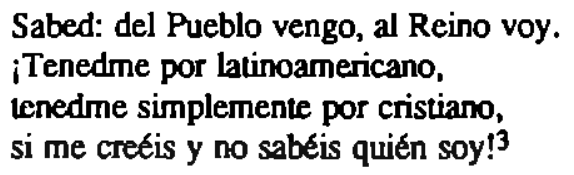

Tal vez sería más prudente, e incluso más cientffico, esperar a que todas su obras hubieran sido editadas y el tiempo hubiera cubierto con su pátina la agitación del presente. Pero uno no puede olvidar la advertencia evangélica contra los que levantan monumentos a profetas muertos (Mt 23,29-32). Dejemos que los muertos entierren a sus muertos $(L C 9,60)$ y sigamos al Dios de la vida en el presente kairós de nuestra historia, aprovechando el mensaje de los profelas de hoy y acompanándoles en su soledad.

Tampoco deseo convertir estas páginas en apología o canonización prematura. $\mathrm{Ni}$ en un estudio de crítica literaria. Como escribía Emesto Cardenal a Casaldáliga, en tiempo de Somoza:

No es tiempo de crítica literaria

$\mathrm{Ni}$ de atacar a los gorilas con poemas surrealistas.

¿Y para qué metáforas, si la esclavinud no es metáfora

ni es metáfora la muerte en el Río das Mortes

si no lo es el escuadrón de la Muerte?

En cualquier caso no pretendo hacer un estudio crítico sobre la poesía de Casaldáliga, poesía que se ha relacionado con la de Unamuno, 5 con la de Whitmann y Mayakovski. ${ }^{6}$

El propósito de estas páginas es más limitado y sencillo: preguntarnos si la poesía de Casaldáliga (dejamos de lado su prosa, muchas veces poética...) es solamente "poesfia religiosa" o auténtica leología poética, diversa ciertamente de la teologia académica, pero legítima y complementaria de la teología profesional, como lo fueron las de Amós, Isajas, Jeremlas ...los poemas de Efrén el Sirio, los cánticos de Francisco de Asis, las secuencias de Jacopone da Todi, los himnos de Tomás de Aquino, la poesía de Juan de la Cruz... Hace antos que en mis escritos y charlas, como introducción o conclusión, he acudido a los versos de Casaldaliga para expresar de forma poética lo que de forma más fría y abstracta había dicho. Quisiera fundamentar más ampliamente lo que de forma intuitiva me parece haber captado hace ya tiempo.

\subsection{Experiencia religiosa y poesin}

La experiencia religiosa no se reduce al lenguaje religioso, pero es una mediación indispensable. ${ }^{7} \mathrm{Y}$ el lenguaje religioso no es simplemente conceptual o lógico, sino que incluye el rico mundo del símbolo, la poesia, el relato, el mito, etc. La poesfa constituye como un estado termico del lenguaje que permite expresar la plusvalía de sentido que el discurso meramente racional no puede soportar. Al poeta le ha sido confieda la palatra, pero no cualquier palabra, sino 
estas palabras originales, prefladas de sentido, que permilen que las cosas sean ellas mismas, y que Rahner ha llamado "protopalabras."8 El poeta es el administrador de las protopalabras, de este sacramento primario de la realidad, que permite dar a luz lo antes oscuro e inexistente. El mismo Casaldáliga dice:

La rosa es ella.

$Y$ sin embargo

solamente es la rosa

si la cantamos. 9

En la palabra poética el poeta encarna todo lo que él es y lo que cree:

No voy,

va mi palabra.

¿Qué más quereis?

Os doy

todo lo que yo creo,

que es más que lo que yo soy. 10

La palabra pośtica participa del misterio de la encarnación y Casaldáliga realiza su tarea poética con conciencia de su misión y con luminosa claridad:

Decir el pan, la lucha, el gozo, el lanto, el monótono sol, la noche ciega.

Verter la vida en libación de canto, vino en la paz y angre en la refriega

Mediterraneamente luminosa

escancio en mi palabra cada cosa, veso de luz y agris de verdad.

Si el Verbo se hace came verdadera, no creo en la palabra que adultera

Yo hago profesión de claridad.11

Casaldáliga une el carisme de la poesla al de su experiencia espiritual, el don de la palabra al ministerio pastoral del obispo. Extratra conjunción que le permite aunar lo que ordinariamente se encuentra disperso:

... LPor qué sembrare versos

delante de este mundo?

Obispo, como un nifo, sin embargo.

Poeta, como un hombre simplemente.

Siempre un poco en sola companfig.

Siempre un poco extranjero en todas partes. 12

Y el poeta espera que par el mero hecho de ser obispo no le pidan que deje de ser hombre:

Nadie me va a pedir

que deje de tener yo mis amores: 
los niños, por ejemplo,

las garzas,

Nicaragua,

"Gero", la vieja gata de verdes ojos sabios,

los libros, un poema,

las cartas, un abrazo,

una canción reciente,

una canción antigua,

Ia tarde recogida bajo la luz domada,

los indios de estos pueblos que fueron tan desnudos,

aquellas viflas viejas de mi lejano pueblo,

América Latina como esposa última,

los pobres de la Tierra,

¡Jesús de Nazaret!13

No es posible distinguir en el poeta, y menos aún en Casaldáliga, la dimensión humana de la religiosa, su vivencia poética de su experiencia espiritual. En su palabra poética se hace carne la Palabra, el niffo y el obispo se dan la mano:

"El poetr es su infancia"

Y el nifo Rilke lo supo.

Todo poeta es un nifio

que se niega a ser adulto.

Podrán crecerle las barbas

de la irs o del orgullo, y caérsele a pedazos

el corazón ya maduro.

Pero conserva los ojos

deslumbradamente puros. ${ }^{14}$

No entenderá a Casaldáliga quien olvida que en él su poesfa es experiencia de Dios y soledad, vida y evangelio, garzas y anhelo de una tierra libre, misterio y transparencia, ira profética y termura ante los nifios, gratuidad y combate por el reino. $Y$ todo ello apasionadamente:

Apasionadamente, eso st. Por ser yo quien soy y porque al decir de Georges Casalis, un escrito teológico sin pasión ya no reflejaria la práctica, la muerte y la vida de Jesús de Nazaret. 15

\section{Raíces}

No es posible comprender a un poeta sin conocer sus raices. Precisamente el obispo misionero entre tribus indigenas del Brasil ha podido valorar la importancia de las raices culurales de la propia lengub. Casaldáliga es catalán de nacimiento. Catalunta constituye hoy una de las zonas más desarrolladas del Estado 
Espantol, tal vez porque ha sabido unir un profundo sentido de la tradición con una gran apertura a la modemidad. Los catalanes son (somos...) por una parte gente trabajadora, pragmática, incluso escéptica, con un cierto sentido común (el seny), pero al mismo tiempo, sontadores, nostálgicos, revolucionarios (la rauxa). Esta tierra que ha engendrado comerciantes e ingenieros, médicos y cientificos, tambien ha dado artistas (Dalí, Miro...), monjes contemplativos (Montserrat, Poblet...), santos (Claret, Vedrung), misioneros (Pedro Claver) y poetas (Verdaguer, Maragall, Espriu, Foix...). Catalufia posee su propia lengua, la lengua matema de Casaldaliga. Este "todavía hoy respira en catalán," 16 nunca ha renunciado a sus raíces, y esta lengua, prohibida en los affos de su infancia y juventud por el franquismo centralista, renunciada luego al dejar su patria, la reencuentra hoy. De hecho Casaldáliga es trilingle, escribe en catalán cuando habla con sus raices, usa el castellano para sus escritos a nivel latinoamericano y el portugues en el cada tha de su pueblo brasileiro. ${ }^{17}$ Las tres lenguas se alteman "como pajaros en ung sola jaula" En un poems ha expresado esta pluralidad linglística suya:

Por tres fuentes me derramo

y no me derramo entero.

El agua más honda y mía

se me estrá quedando dentro.

Jo, yo, eu.

Ninguno.

Los tres.

Por tres lenguas digo más, tres lenguss me dicen menos.

Si las tres son fuentes mins solo yo soy el venero. 18

A traves de estas tres lenguas alcanza universalidad. Pero seguramente ninguna se adecía a su experiencia. El dolor de todo poeta se acrecienta por la fragmentariedad de cada lengua. Nosotros nos limitaremos a su poesía en lengua castellang 19

\subsection{Blobibliografio}

Casaldáliga neció en Balsareny (provincia de Barcelona) en 1928. Su padre posela una lecheria Su infancia coincidió con la guerra civil espattola (19361939). Muy joven, aún ingresó en el seminario menor de la diócesis de Vic, ubicado en el santuario mariano de $\mathrm{La}$ Gleva. Ha recordado aquellos aflos en un poema:

Instinto de soledad.

Vocación de companfí.

Mercaderes y tratantes. 


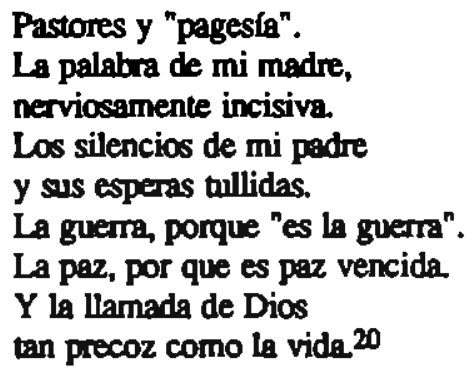

El deseo de ir a "las misiones" le impulsó a ingresar en la congregación claretiana de los Misioneros del Inmaculado Corazón de María y comenzaron los alos de formación (Cervera, Barbastro, Vic, Solsona, Valls) que culminaron con la ardenación sacerdotal en el Congreso Eucaristico de Barcelona en 1952, de manos de Mons. Abel Antezana, obispo de La Paz. De 1952 a 1958 trabaj6 en el colegio de los claretianos en Sabadell, el 58 pasó a Barcelona, donde tuvo una múltiple actividad pastoral, que lo llev6 a viajar a Guinea para promover los cursillos de cristiandad. En 1961 fue prefecto del seminario claretiano de Barbastro, pero al poco tiempo estaba ya en Madrid, director de la antigua revista Iris de paz y en plens tarea pastoral y literaria El 67 asistí como delegado en Roma al ceppínlo claretiano de renovación, exigido por el Vaticano II. Un afio más tarde en 1968 fué enviado al Mato Grosso, Brasil, a la misión claretiana de Sao Félix, entre los ros Araguaia y Xingú, lugar de extrema pobreza, sin médico, ni correo, ni luz, ni teléfono, ni telégrafo, analfabetisno y opresión por parte de los latifundios y las grandes instituciones latifundistas (Sudam, Codeara...). En 1970 escribio un relatorio sobre Esclavitud y feudalisme en el norte del Mato Grosso, que no paso inadvertido. Comenzo a recibir advertencias de los terratenientes y latifundistas, $\mathrm{C}$ incluso de "voces amigas" de la Iglesia, rogándole que no se entrometiera en estas cuestiones ajenas al ministerio sacerdotal. La policía federal controlo sus pasos.

En 1971 fue nombrado obispo de la recién erigida prelatura de Sao Félix: su mitra fue un sombrero de paja sertanejo, su béculo un remo de madera, su anillo episcopal fue enviado a su madre... Su primera carta pastoral es ya progranática: Una Iglesta de Anazonia en conflicto con el latifundio y la marginación social. Pronto comenzaron las reacciones negativas. En este tiempo escribió ${ }_{i} Y o$ creo en la justicta y la esperanzal en la serie El credo que da sentido a mi vida ${ }^{21}$ y las colecciones de poemas Clamor elemental 2 y Tierra nuestra, liberiad.23 La prelanrra de Seo Félix comenzo a ser perseguida, su obispo fue acusado de subversivo y de comunista por los terratenientes, e incluso por el obispo de Brasil Sigaud quien pidió que Casaldáliga fuera expulsado del país. Las cartas iban y venían a la nunciatura y a Roma. El peligro de expulsión cedió, pero creció el peligro de muerte. Hubo tres intentos de asesinato. La muerte acabó con la vida de muchos peones anónimos, de indios, de los padres Rodolfo y Joan Bosco P. Bumier, quien cayó asesinado junto al obispo, por protestar contra la tortura que 
la Ribeirao Botino, la policf́a, realizo a una pobre mujer cuyos gritos escuchaban. De esta época es La muerte que da sentido a mi credo. Diario 1975 77,24 con su Romancillo de la muerte.

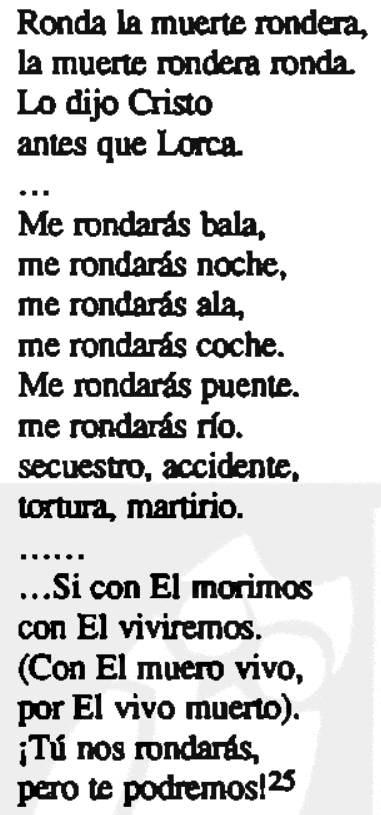

Siguió la pasión del pueblo y de su obispo, hubo nuevas amenazas, pero prosiguió su trabajo: visitas pastorales, encuentros con agentes de pastoral, celebraciones, corresponsabilidad con la conferencia episcopal de Brasil (CNBB), con la comisión de pastoral de la tierra (CPT), con el consejo indigenista de Brasil (CIMI). En esta época publico En rebelde fidelidad. Dirrio 1977-83,26 Experien- cia de Dios y pasión por el pueblo,27 Misa de la Tierra sin males,28 Fuego y ceniza al viento. 29

En julio de 1985, Casaldáliga se sintió movido a visitar Nicaragua, para unirse a la "insurrección evangélica" del ayuno y oración que promovia su canciller, Miguel D'Escoto. Fue a Nicaragua a ejercer el ministerio de "la consolación" y de la "frontera." Fue la primera vez que abandonó el Brasil desde que llegó en 1968. Viaje insólito, que tuvo el respaldo de unas 200 entidades eclesiales y civiles y de 23 obispos del Brasil, pero que, evidentemente, resulto conflictivo para algunos sectores de la Iglesia de Nicaragua, en contra del proceso sandinista. Tambiên visito El Salvador (la tumba de Romero y el hospitalito donde fue asesinado) y Cuba Su experiencia centroamericana y caribefia ha quedado plasmada en Nicaragua, combate y profecla 30 y en el libro de poemas El tiempo y la espera. ${ }^{31}$ Impactado por la situación del pueblo y de la Iglesia, prometió visitar nuevamente Nicaragua. Lo hizo en marzo de 1987. También visitó a los refugiados guatemaltecos en México y Panamá. Desistió de visitar outros palses para evitar 
conflictos intraeclesiales. ${ }^{32}$

Compafiero y promotor de Casaldaliga es su hermano claretiano Téfilo Cabestrero. A él debemos el que se hayan publicado muchos escritos de Casaldáliga y otros complementarios. ${ }^{33}$ Seguramente sin su fiel y eficaz colaboración no le hubiera sido posible al obispo de Sao Félix publicar muchas de sus obras.

Con esta introducción podemos ya adentramos a estudiar el itinerario poetico de Casaldáliga y sus principales temas y símbolos teológicos. Siempre con temor y temblor, pues al reflexionar sobre la teologia subyacente a su poesfa existe el peligro de convertir.

\section{la mariposa úlima}

-crema, limón, canario-

que acaba de latir entre mis ojos

borrachos de hermosura... ${ }^{34}$

en un pobre animalito, muerto y disecado, clavado con un alfiler y puesto en una vitrina, para el estudio del coleccionista......

\section{Itinerario}

No es un simple itinerario cronológico, como si se tratara de etapas que Casaldáliga ha ido recorriendo en su caminar poético. Es más bien, y además, un proceso circular y sincrónico, que siempre se halla simultáneamente presente y siempre se va repitiendo de nuevo.

\subsection{Tierra-sin-males}

Con este título, que evoca la obra de Casaldáliga sobre el mundo indigena hoy destruido, queremos destacar todo el mundo de belleza y luminosidad que el poeta contempla y que es la creación recién salida de las manos de Dios y, al mismo tiempo, una anticipación de la nueva tierra. La luz matinal se mezcla con la escatológica, es génesis y apocalipsis, el génesis anticipa la nueva creación:

Entonces vere el sol con ojos nuevos

y la noche y la aldea reunida;

la garza blanca y sus ocultos huevos,

la piel del río y su secrela vida.

...

Confluyendo en la paz de Tu Mirada, vere por fin, la cierta encrucijara

de todos los caminos de la Historia

y el reverso de la fiesta de la Muerte

¡Y cebare mis ojos de tu Gloria,

para ya siempre más ver, verme, verte! 35

Todo cuanto contempla con mirada de poeta y ojos de nifio es, a la vez, naturaleza y gracia, belleza creada y luz de la fe: 
- los ríos, el Araguaia, inmenso y lleno de belleza:

Nuestras vidas son los ríos

IMi vida es este Araguaia!

Indescriptible.

Indescifrable.

Que se ama y se agradece, y se teme y se desea;

al que se vuelve siempre,

como a un hogar fatidico y dichoso. ${ }^{36}$

—el jardín:

Riego las hojas verdes y sus gritos effmeros.

Los protejo del viento huracanado,

del sol calcinador. Doy cada día

tres o cuatro miradas protectoras,

y sorprendo la Creación haciéndose...37

-la lluvia:

llueve tan manso ahora

que se empapan las cosas, con el alma,

de una gracia de Dios hecha bautismo agreste. ${ }^{38}$

-la garza blanca, por la que el poeta siente una especial predilección, pero que no es simple belleza animal, sino símbolo sorpresivo del Espiritu:

El Espíritu que aflora

en una cosa cualquiera.

¡Y toda el alma caída

se pone en pie tan seffera...I

Porque le basta a la vida

saber que hay corriente franca

y encontrarse en la ribera

con alguna garza blanca ${ }^{39}$

La garza blanca es símbolo de la buena nueva y de la nueva creación:40

Garza blanca, adiós

pequefla

Buena Noticia de Dios.

Signum credibilitatis

de la Nueva Creación. ${ }^{41}$

Por esto el poeta dice que si no hubiera garzas blancas después de la muerte, quedaria decepcionado. 42

-la noche ${ }^{43}$, el ocaso ${ }^{44}$, la tarde:

La tarde es otra vez azul y verde

y en las nubes se esponja la alegria 
El corazón más sabio, está de vuelta

$y$ ha crecido, en la tarde, la Esperanza. ${ }^{45}$

-el mar:

El mar que soy, el mar que me convida,

de donde viene, a donde va mi vida,

el mar que nunca habré de terminar. ${ }^{46}$

-el amanecer.

El lago y yo amanecernos llenos

de Dios, de Dios, de Dios... ${ }^{47}$

-la colina:

Colina, verde colina

única; peldafio hoy

de las Bienaventuranzas;

maftana de la Ascensión. ${ }^{48}$

Pero sobre todo son las personas humanas las que suscitan su admiración y ternura:

-los niffos:

Cariflosos

Pasmados

Juguetones

Inertes

Chapoteando, libres, en los charcos.

Desnudos en la lluvia.

Revestidos de sol

o de mosquitos. ${ }^{49}$

-y la aldea de indios Tapirape:

Si no muero a pistola de capanga, por los caminos, lejos, como un peón huido;

si no me entierran por su propia cuenta,

la floresta o el río, bajo un ipé o entre garzas blancas:

enterradme en la aldea luminosa,

dentro de vuestro barro y vuestras palmas.

...

colgado en una red de algodón bueno,

plantado y recogido y cardado e hilado y tejido

por esas manos indias, creadoras,

un día y otro día (una luna y otra, sobre todo

cuando el Viento no estorba el juego leve del algodón y callan

con la Noche, la Prisa y el Progreso; 
cuando Dios se pasea, todavía

por esta Aldea pura

de antes del Pecado). 50

-en fin, suefla en la tierra de la Liberlad:

Esta es la Tierra nuestra:

¡La libertad,

humanos!

Esta es la Tierra nuestra:

ila de todos

hermanos! 51

Esta tierra sin males, ¿es utopia? ¿Es esperanza? ¿Es realidad anticipada? ¿Son los ojos puros del poeta los únicos que la pueden contemplar? ¿O es el vidente que, como Moisés, ve a lo lejos la tierra prometida?...

\subsection{Ira}

Esta visión de la tierra sin males, soflada, esperada, entrevista a lo lejos, contrasta brutalmente con la realidad de cada día. El poeta lanza su airada protesta, con ira, sin odio, pero sin falsa paz:

Sé que estos poemas podrán parecer, a veces iracundos, amargos, tristes. Pienso que también esto es evangélico. La amargura o la tristeza no niegan la Esperanza: la purifican (la comprometen), le dan su razón de ser desile abajo, la multiplican repartiéndola ${ }^{52}$

Sus maldiciones comienzan estigmatizando al latifundio y sus aliados:

Maldito sea el latifundio salvo los ojos de sus vacas.

Maldita sea la Sudam. su amancebada.

¡Maldita sea para siempre

la Codeara! 53

$Y$ en otro lugar:

¡Malditas sean
las cercas vuestras,
las que os cercan,
por dentro,
gordos,
solos,
corno cerdos cebados;
cerrando
con su alambre y sals tínlos,
fuera de nuestro amor
a los hermenosl




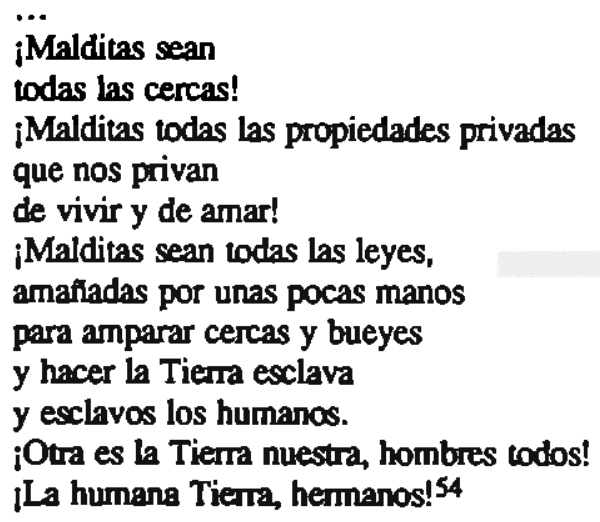

Casaldáliga es consciente de la dureza de sus invectivas contra el latifundio, de la cual el hijo del lechero sólo salva a las vacas... Sabe que le comienzan a llamar subversivo, pero no teme esta acusación:

Me llamarín subversivo.

$Y$ yo les dire: lo soy.

Por mi pueblo en luche, vivo.

Con mi pueblo en marche, voy.

Tengo fe de guerrillero

y amor de revolución.

$Y$ entre evangelio y canción

sufro y digo lo que quiero.

Incito a la subversión

contra el Poder y el Dinero.

Quiero subvertir la ley

que convierte al Pueblo en grey

y el Gobiemo en camicero.

Tengo menos paz que ira, tengo más anor que paz. 55

Otro capftulo de su encendida protesta es el que corresponde a los pueblos indIgenas, masacrados duranie siglos. Toda su Proclama indigena debería ser citada:

No acepteis ni proyeclos, ni promesas,

ni limosnas, ni lágrimas inútiles.

Exigid

con recibo de raices y sangre

el supremo derecho que os cabe!

INo querais ser postal televisiva de Presidente

o Nuncio, 
agenda del Ministro en reportaje

o granja de Autarquía...l

¡Rehusad ser vitrina arqueológica de fósiles

para-humanos, nombre de calle exótico, deshonra en calle, río sin memoria, festiva nostalgia de falso camaval de un Pueblo victima...!!56

Su indigración toma caracteres todavía más duros cuando se dirige al imperio, al césar, al farán, al sistema, al pretorio, a Brasilia y a Washington. La Oda a Reagan es paradigmática Comienza así:

Te excomulgan conmigo los poetas, los niffos, los pobres de la tierra ${ }^{57}$

$Y$ concluye con una terrible maldición:

¡Yo juro por la sangre de Su Hijo,

que otro imperio mato,

y juro por la sangre de América Latina

$\rightarrow$ preflada de auroras hoy-

que tí

serás el último

(grotesco)

emperador! 58

A este imperio le acusa de la agresión contra Nicaragua y de la muerte de Monsefiar Romero:

\author{
Pobre pestor glarioso \\ asesinado a sueldo \\ a dólar \\ a divisa \\ como Jesís por orden del Imperio. 59
}

Su denuncia se dirige también a la Iglesia Casaldáliga, como aquel niño del viejo cuento de Andersen sobre el vestido del rey, se atreve a decir lo que todos ven, pero nadie osa denunciar. Su crítica a la Iglesia no se dirige a la esposa de Jesís, sino a cuanto tiene de prostitución. Sus símbolos son la curia, la sinagoga, el sinedrio, el templo. Lamenta su falta de carisma, critica todo cuanto asfixia el viento del Espfritu. En una cración a San Francisco le dice:

Nuestra madre Iglesia
mejoro de modos
pero hay mucha curia
y carisma poco.60

En su poema en homenaje a Romero escribe unos versos que posiblemente tienen resonancias autobiograficas: 
¡Pobre pastor glorioso, abandonado

por sus propios hermanos de Báculo y Mesa...!

(las curias no podían entenderte:

ninguna sinagoga bien montada puede entender a Cristo). ${ }^{61}$

Y a Juan Pablo II le recuerda:

La curia está en Belén

y en el calvario

la basilica mayor.

Es hora de enfrentar al nuevo imperio

con la púrpura antigua de la pasión. ${ }^{62}$

Y en el poema titulado, Deja la curia Pedro, exclama con fuerza:

Deja la curia, Pedro,

desmantela el sinedrio y la muralla,

ordena que se cambien todas las filacterias impecables

por palabras de vida temblorosas.

...

Legión de mercenarios acosan la frontera de la aurora naciente y el César los bendice desde su prepotencia.

En la pulcra jofaina Pilatos se abluciona, legalista y cobarde.

El Pueblo es solo un "resto",

un resto de Esperanza.

No lo dejemos solo entre guardias y principes.63

Y recordando a Rahner escribe en Salmo de abril en Sao Paulo:

"Es invierno en la Iglesia" advertía Karl Rahner, haciendo testamento de proleta.

(y el frío es la tristeza del Mundo

$y$ el inviemo

es pecado en la Iglesia que ha abrasado el Espiritu). ${ }^{64}$

También lamenta que Puebla no haya sido más audaz:

¡Puebla, esperanza frenada

de esta America tendida

entre la Cruz y la Espadal

iAy Celam que nos recelas, amarrando Viento y velas

cuando el mar es quehacer!65 cribe:

Y recordando la primera evangelización, tan exaltada por algunos sectores, es-

"Llevaban la espiga"

"Llevaban la rosa"

(y tambien la espada)

(con muchas espinas) 


\section{"Y los mandamientos" \\ "Y el avemaria" \\ (todos conculcados) \\ para la Amerindia). ${ }^{66}$}

Y en la Mise de la tierra sin males, contrapone:

El amor del Padre de todos

me bautizo con el Agua de la Vida y de la Conciencia

y sembró en mi la Gracia de su Verbo,

Semilla universal de Salvación.

- Mientras nosotros te herramos

con un Bautismo impuesto,

divisa de seres humanos,

blasfemia del Bautismo,

violación de la Gracia

y negación de Cristo. 67

"Portadores de la Muerte, misioneros de la Nada" califica el obispo a los abusos de la primera evangelizacion ${ }^{68}$

\section{Tiempo de pesion}

La ira nace del sufrimiento y conduce a un nuevo sufrimiento. La pasión del pueblo es la pasión del Seftor y se convierte en pasión del obispo. Mueren nifnos inocentes, como Maria Rita:

Ella, Marla Rita, era dos ấos sólo,

dos negros ojos puros de costosa promesa

$\cdots$

El Pueblo se alz6, un dib, de levante

contra la Codeara omnipotente.

Los soldados, vendidos, controlaban la puerta de lodos los senderos.

Marla Rith, enferma, no pudo salir más:

no pudo crecer más, la flor pequefia,

y murib, con la tarde del sertao redimido,

$\rightarrow$ rosa de libertad, segada niña-

......69

Mueren poseiros asesinados, mueren los indígenas "mártires, siempre-mártires:"

Es tiempo de Pasión

en la liturgin,

en la tierra violada,

en la lucha, en la agonfa de estos Pueblos

primeros, 
en la tenaz incertidumbre de mi pueblo

siempre preterido...

¿Sera tiempo de Pascua

en la encendida Pasión que nos hermana, de

Norte a Sur, del Poniente a la Aurora?70

Es tiempo de pasión en Nicaragur:

INiria novia del Dig prometido,

bautizada en la sangre,

grávida de Esperanza

$$
\text { y violadal } 71
$$

$\mathrm{Y}$ al besar los féretros de sus jóvenes asesinados, el pastor exclama:

El muerto es tambien mío,

hijo de mi esperanza.

Su sangre es ya cosecha

de mi implacable grito

$$
\text { ¡Reino adentro! } 72
$$

En este tiempo de pasión, América Latina se cubse con la sangre de mártires como Romero:

¡San Romero de América, Pastor y Mártir nuestro!

Romero de la paz casi imposible en esta tierra en guerra.

Romero en flor marada de la Esperanza incólume de todo el Continente.

Romero de la Pascua latinoamericana 73

Aunque a veces, la misma Iglesia, por miedo, oculta sus propios mártires, como sucede con Enrique Angelelli, obispo argentino y mártir prohibido:

Caíste en el camino, desabrochando el Llano, con los brazos abiertos en asumida cruz (mientras agosto calcinaha el odio, chapado en las guerreras).

Mientras la Iglesia echaba sus cerrojos prudentes, negándose a la muerte $y$ a la Resurrección. ${ }^{74}$

Es toda America Latina la que vive en tiempo de pasión:

Dios, pobre y masecrado, grita al Dios de la vida

desie esta colectiva cruz

$$
\text { alzada }
$$

contra el sol del Imperio y sus tinieblas, ante el velo del Templo estremecido, Mafana sera Pascua

$\rightarrow$ porque El es ya matiana para siempre- 
Pero hoy es todavia viemes Santo.

Todos somos testigos, entre dados y lanzas, mientras la madre llora sobre el hijo caldo.

Yo no quiero negarme a este misterio.

¡Yo no quiero negartel

América Latina

será mi cruz

definitivamente. ${ }^{75}$

Por esto mismo, cuando le dice a Pedro que deje la curia, aflade:

Vamos al Huerto de las bananeras, revestidos de noche, a todo riesgo, que alli el Maestro suda la sangre de los Pobres.

La túnica inconsútil es esta humilde came destrozada, el llanto de los nifios sin respuesta, la memoria bordada de muertos anónimos. ..

Es hora de sudar con Su agonía, es hora de beber el cáliz de los Pobres y erguir la Cruz, desnuda de certezas, y quebrantar la losa-ley y sello-del sepulcro romano y amanecer

\section{de Pascua 76}

Toda esta sangre se convierte en eucaristía martirial, como en las eucaristías de Romero:

Tú ofrecíns el pan,

El Cuerpo vivo

-el triturado cuerpo de tu pueblo;

su derramada sangre victoriosa-

la sangre campesina de tu pueblo en masecre

Ique ha de tefir en vinos de alegria la aurora conjurada!

...

$Y$ supiste beber

el doble cáliz

del altar y del pueblo

en una sola mano consagrada al Servicio. 77

Este sufrimiento del pueblo se convierte en sufrimiento de su pastor, al que la muerte ronda ${ }^{78}$, el cual en una profecfa extrema ratifica:

Moriré de pie como los árboles.

Me matarán de pie.

El sol como testigo mayor, pondrá su lacre

sobre mi cuerpo doblemente ungido. 
Y los ríos y el mar

se harán camino

de todos mis deseos,

mientras la selva amada sacudirá sus cúpulas de júbilo. ${ }^{79}$

$Y$ ante el temor de ser expulsado del país exclama:

No me importa que me expulsen.

Yo soy tesbita llamado

y sé pasar el Jordán.

Toda tierra es cautiverio, toda tierra es reconquista

toda tierra es patria nuestra.

...

No me importa que me expulsen.

Nunca saldre de mi casa ${ }^{80}$

Otras veces siente la soledad de la dura prueba:

La soledad por fin

la lejana y la proxima

La soledad total.

¿Dónde están los caminos conocidos?

¿Es esta la última vispera?

¿Por qué me abandonaste? ${ }^{\text {B1 }}$

Y experimenta el cansancio de esperar, de todo:

Cansado, todo entero, del cansancio

de tantos compafteros de camino

- Isi es que se cansaron! -

Cansado de esperar, en todo caso siempre.

De vivir, de esperar.

Cansado y descansado en la Esperanzal 82

Por esto su oración al Seflor, al sentirse perseguido y enjuiciado es un clamor ardiente:

Mi Fuerza y mi Fracaso eres Tú.

Palabra de mis gritos, Silencio de mi espera, Testigo de mis suefios. ¡Cruz de mi cruz!

Causa de mi Amargura, Perdón de mi egolsmo, Crimen de mi proceso, Juez de mi pobre llanto, 


\section{Razon de mi Esperanza, ¡Tú!83}

Es viemes santo, tiempo de pasión y de cruz, de alianza entre el pretorio y el templo, mientras Pilato se lava las manos y el pueblo es masacrado y suda en el huerto de las bananeras. Pero la cruz no es la última palabra...

\subsection{Esperanza contra toda esperanza}

En medio de tanto dolor, Casaldáliga lanza siempre un grito de esperanza No es la esperanza que nace del optimismo psicológico o de una confianza meramente sociológica en las fuerzas de la historia. Es una esperanza con mayúscula, que nace de la pascua. No es una esperanza fácil, es un esperar contra toda esperanza, como Abrahán ( $R m$ 4,18), que no debe apoyarse en cálculos numéricos, sino fiarse en Dios:

Contempla las estrellas,

Abrahán.

No intentes numerarlas.84

Es la esperanza de Maria:

Sefiora de la Esperanza, porque creíste en la Pascura, porque palpaste la Pascua, porque comiste la Pascua, porque moriste la Pascus, porque eras Pascua en la Pascua ${ }^{85}$

Es una esperanza que se profesa junto con la justicia y la libertad:

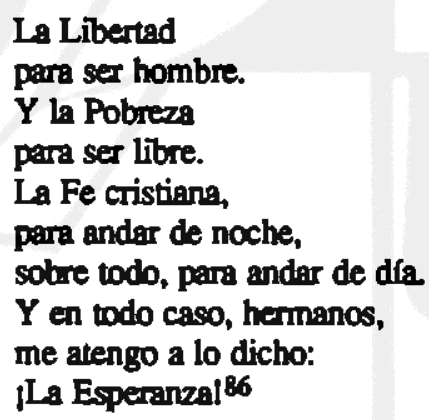

Pero esta espenanza no frena la lucha, al reves, la fuerza:

Saber esperar, sabiendo al mismo tiempo forzor las horas de aquella urgencia que no permite esperar...87

Por todo ello, esta esperanza se convierte en combate, en rebelde fidelidad, en espera ardiente e insurrección evangélica, en apoyo a todas las causas del reino, en 
colaboración con todos aquellos que luchen por la justicia. Esto ha escandalizado a muchos, pero el obispo es muy claro: el evangelio es la rafz de su rebeldía, el reino su horizonte, la pascua el fundamento de su utopía, la sangre de los mártires es la semilla de la tierra-sin-males:

Unidos en la memoria
de la Pascua del Sefior,
volvemos a la Historia
con una deuda mayor.
...
America Amerindia,
todavía en la Pasión
un día esta ul Muerte
tendrá Resurrección.
La Pascua que comemos
nos nutre de porvenir,
seremos en tus Pueblos
el Pueblo que ha de venir.
Los Pobres de esta Tierra
queremos inventar
esta Tierra-sin-males
que viene cada maflana

Este aliento le anima a dedicar un poema a Che Guevara (que su hija le agradeció cuando Casaldáliga visito La Habana):

Descansa en paz. $Y$ aguarda seguro, con el pecho curado del asma del cansancio; limpio de odio el mirar agonizante; sin más armas, amigo, que la espada desnuda de tu muerte. (Morir siempre es vencer desde que un dla

Alguien murió por todos, como todos, matado como muchos...) 89

Esta pasión por una tierra nueva nutre su amor a Nicaragua, a la que piropea marianamente:

Toda hermosa sos,

las dos:

jla Purísina y vos 190

No se trala de ingenuidad, ni de moda, sino de pasión por la justicia y esperanza en la tierra nueva y libre que anhelamos todos:

Para que la Libertad de la Nueva Nicaragua

-que Sandino soñó en la montaña- 
llegue a ser la entera libertad:

aquella libertad con la que Cristo nos liberó.

Para que la Liberad de la Nueva Nicaragua

fermente la entera liberación

de la Nueva América que sollamos. 91

Y glosando el título del libro del comandante Omar La montaña es algo más que una inmensa estepa verde, exclama el obispo:

La montafla es todo un Pueblo

- verde antiguo, verde nuevo-

que ha resuelto despertar.

La montafta alcanza el cielo

y conquista la ciudad

y cobija nuestros muertos

asegura nuestra Paz.92

Por esto le puede decir a Reagan:

La sangre de nuestros mártires sustenta nuestros brazos

y en nuestras bocas se hace cántico y surtidor.

Tí nunca has visto la montalia, Reagan,

ni has oído en sus pájaros la voz de los sin voz.

Tú no sabes de vida,

ni entiendes de canción. ${ }^{93}$

Y le puede dedicar un libro a Fidel Castro:

-en la Esperanza

de construir el Dia de la Justicia y La libertad 94

Es una esperanza comunitaria y cristológica al mismo tiempo:

Porque lo espero a El y por que espero

que al encontrarlo, todos nos veamos

restablecidos por el sol primero

y el corazón seguro de que amamos;

...

porque aprendf a experir a contramano

de tantr decepcion: te juro, hermano,

que espero tanto verlo como verte.95

De este modo el itinerario se cierra por donde habín comenzado; por la tierrasin-males, vista, sollada, adivinada, coperada.

libres de indo pecado

de toda explotacion

-Cielos Nuevos, Nueva Tierra-

ros, garzes, hombres, Dios!96 


\subsection{Conclusión}

Al acabar este itinerario poético, ¿qué conclusiones podemos sacar ya para nuestra búsqueda teológica?

Ciertamente Casaldaliga no es, ni pretende ser, un teólogo profesional, ni éste es su carisma. Pero su poesla es realmente profética. Su visión de la tierra-sinmales es un anuncio no sólo del presente, sino del futuro escatológico de Dios, es una buena nueva anunciada poéticamente a través del Araguaia o del vuelo ligero de las garzas blancas. Su ira es la denuncia fogosa de todos los profetas ante el pecado, ante la injusticia, ante los contubernios entre el templo y el imperio, ante la muerte del pueblo inocente. El sufrimiento del pueblo es sufrimiento del profeta, quien como el Siervo de Yahvé carga con la pasión del pueblo, sufre con él, y adivina, misteriosamente, al Siervo Jesís quien con su cruz quita el pecado del mundo. La esperanza es el anuncio profético de consolación y de una tierra nueva, sin fronteras ni cercas, en los momentos en que el pueblo sufre destierro y cautiverio. La urgencia de luchar es la exhortación de todos los profetas a cambiar los corazones y la tierra y a caminar humildemente, ante la presencia de Dios, confiando en que la utopla sera realidad.

Si todo poeta es profeta y vidente en medio de la noche, si todo obispo debe ser profeta, como recuerda el mismo Casaldáliga citando al Cardenal Marty, la palabra del obispo poeta Casaldáliga sintetiza ambas funciones en su palabra de fuego y en sus versos duros y transparentes. Denunciar, anunciar, alentar a transformar el mundo y a mantener la esperanza escatológica del pueblo, esta ha sido siempre la función de los profetas, desde Elsas el tesbita a Jesús de Nazareh pasando por los profetas que escribieron en poemas sus orficulos. Como el profeta Jerenías (Jer 20,7), tambien el se ha dejado sechucir par el Sefior.

Me has sechucido, Sentor,

y me deje seducir,

desde que aprendi tu nombre

balbuceado en familia.

Me has seducido, Seflor

y me deje sectucir

en cada nueva llamada

que el alto mar me traía.

$\cdots$

Me has sectucido, Sentor

y me dejé sedurir

cada rostro de potre

que me gritabe in Rostro.97

En la rafz de toda profecta hay un profunda experiencia expiritual. Cesaldáliga, como Elfes el resbita que huye del imperio,93 tambien tiene su monte Cermelo. El corazón de la profecia es el misterio de Dias. Veamos como lo expresa Casaldálige (Continuara). 


\section{NOTAS}

1. P. Cuncldiliga, El tiempo y la espera, Smander, 1986, p56.

2. P. Canald liga, Nicoragua, combate y profech, S. Jose, 1987, pp. 69-70.

3. "Identided" El siempo y Le espera, p. 13.

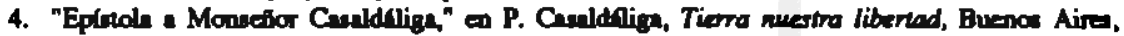
1974. pp. VVI-VIII

5. JM. Valverie, "Prologo" El siempo y Lo espare, p. 7.

6. C. Fomer, presenteción de P. Centhlige, Encora ovi respiro en catalk, Bureelone, 1987, p. 7.

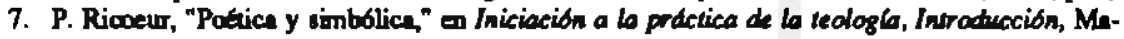
drid, 1984, pp. 43-68.

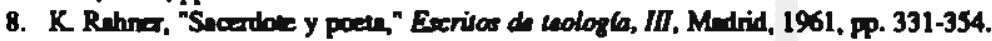

9. "Le rous," El tiempo y b espero, p. 71.

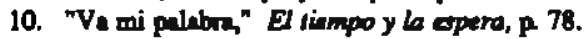

11. "Clarided," El tiempo y b epera, p. 15.

12. "Salno de abil en Seo Paulo," El tiempo y be epere, . p.42; of. "Menuje a Salvador Epprin," Tiarra nuestre, libertad, pp. 142-143.

13. "Por are mero hecho de ver obiqpo." El tianpo y la espere, pp. 59-60.

14. "El poen," El tiempo y lo erpare, p 118.

15. P. Canaldiliga, La miva de la Tierra sin males, Bitheo, 1980, p 28.

16. P. Ceneld lign, Eneara aviv respiro an calald, Barcelene, 1987.

17. P. Cenaldaign, Experiancia do Dios y pasion por al pueblo, Santmider, 1983, p. 15.

18. "Jo, yo, Er," EJ tienpo y la eqpera, p. 114.

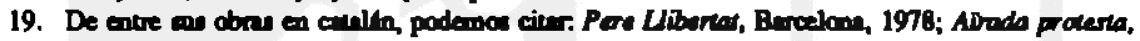

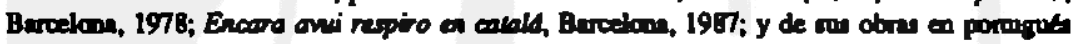

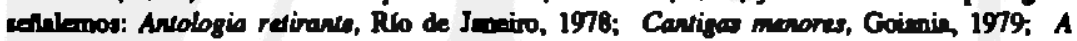
Cuia de Gedeso, Peirtpolin, 1982; Miseo de Tara anm males, Rfo de Janeiro, 1980.

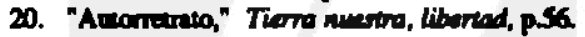

21. IYo oreo an la jurticia y le esporumbl, Bliteo, 197.

22. Clanor alamened, Selemence, 1971.

23. Tiere numbre, libured, Buenos Aires, 1974 (TN).

24. La muote que do santido a mi credo. Diwio 1975-J977, Bibmo, 1978 (MC).

25. MC, pp. 13-14.

26. En robelde fidelidad Diario 1977.1983, Bilhea, 1903 (RP)

27. Experiencio de Dias y pasion por al pueblo, Serrender, 1993 (EP)

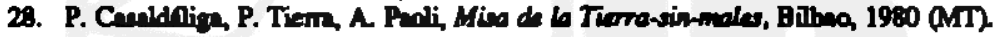

29. Fungo y canica al Vionso, Senunder, 1986 (FC).

30. Ninorafuo, combale y profecto, San Jow, 1987 (CP).

31. El tiempo y b epero, Sentrinder, 1986 (TE)

32. Cfr. Vida Numa, in 1579, 1589, 1590.

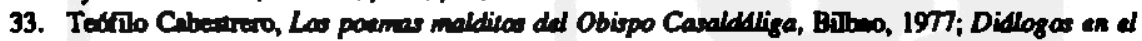
Mato Grasso con Pedro Casoldeliga, Sel mance, 1978; Un grito a Dios y al mindo, Sin Jout, 1986.

34. "Beilnea profocen," TN, p. 65.

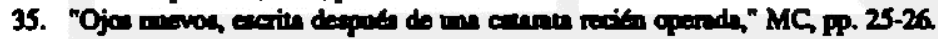

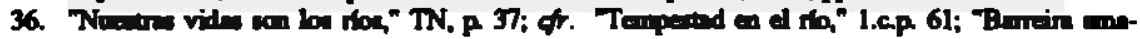

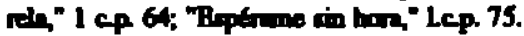

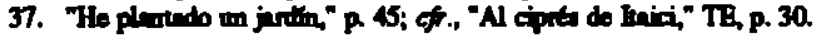

38. "La llovien," TK, p. 47.

39. "Le para biene," TN, p. 52.

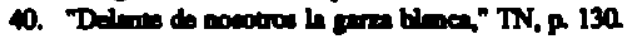


41. "Pequefin proferifon de experang werl," TN, p. 147.

42. "Si no hubiere garas blmas," TE p 106.

43. "Nocumo," TN, p. 55; "Espenime in hon," TN, p. 75.

44. "En la vergitenn del $0000, "$ TN, pp. 6263.

45. "Convilecencir," TN, p. 90.

46. "Mar de Seo Mreere," TE, p. 29.

47. "Ammecer," TE, p. 44.

48. "Colin,", TB, p. 87.

49. "Brou nillow," TN, p. 92; "Vanderlis," TN, p. 76.

50. "Alden Tapirepe," TN, p 122

51. Tiem neerse, liberted," TN, p. 128.

52. "Noen preliminer" a Tierre nuesto, libertad

53. "Alsbonas y maldicionea del 3 de merzo," TN, p. 115.

54. "Tiem noetre, liberted," TN, Pp. 128-129.

55. "Cencito de la boe y el haz," TN, Pp. 117-118.

56. "Prockme indirene," MT, p. 73.

57. "Ode a Reron," C., p. BS.

58. "Odn a Reagen," CP, p. 86.

59. "Oscr Amulfo Ramer," EP, p 238.

60. "Oncion a Sen Prancicos en forma de dershogo," RC, p. 61.

61. "Oucar Amulfo Ramero," EP, p. 238.

62. "A Jun Pablo II," FC, pp. 76-77.

63. "Deje le curin, Pedro," TE, Pp. 48-49.

64. "Selmo de abril en Seo Paulo," TB, p. 39.

65. "Puetin," RF, p. 49.

66. "Los conquiredore (Completendo a Pemfn. Y aviando, a tiempo, parn la cormemoraciones de los 500 atos...)," TE, p. 117.

67. Mies do b Torrasin-males, p. 44.

68. Ihid.

69. "Marn Rins," TN, pp 126-127.

70. "Prochme indigenn," MT, p. 69.

71. "Centrombrice," EP, p. 183.

72. CP, p. 70.

73. "Oucro Amnifo Ramero," BP, p. 237.

74. "Mnneser Anclelli, on mitir pochibido," BP, p. 233.

75. "Amtrion L ine, TB, p. 62

76. "Deje la curis Petro," TR, p 48.

77. "Ovar Almolfo Romera," EP, p. 237.

78. Rommeillo de le moerte" MC, pp. 13-14.

79. "Profecin extreme rationde, TN, p. 97.

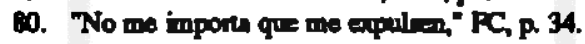

81. "Pruebs," TN, p 84; cfr. "Ausencies," TN, p. 133-134.

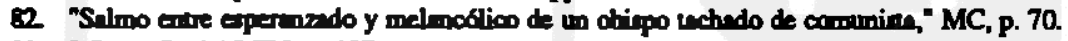

8. "Setir Jexul," TN, p. 137.

84. "Abrahtn, FC, p. 72

85. "Sedon de heperms," FC. p. 58.

86. "Rplogo shieno," TN, p. 148.

87. "Reatificadín," TN, p. 86

88. MT, \& 56

89. "Co, Goovan" TN, p. 40.

90. "Piropo Nicangors, CP, p. 125.

91. CP, p. 34.

92. CP, p 47. 
93. "Odn \& Rengen," CP, p. 86.

94. CP. p. 133.

95. "Boptrune umbitn," TR, p. 26.

96. "Pequefin profesita de expertinze wonl," FC, p. 92.

97. "Me has weducido, Seftor," FC, p. 92.

98. "No me importe que me exputsen," FC, p. 34. 